\title{
Sociodemographic correlates and family aggregation of leukocyte telomere length in adults and children from Mesoamerica
}

\author{
Kerry S. Flannagan' | Erica C. Jansen' | Laura S. Rozek ${ }^{2}$ ｜ Katie M. Rentschler ${ }^{2}$ | \\ Ana Victoria Roman ${ }^{3}$ ｜ Manuel Ramirez-Zea ${ }^{3}$ ｜ Eduardo Villamor',4 | \\ For the Nine Mesoamerican Countries Metabolic Syndrome Study (NiMeCoMeS) Group
}

${ }^{1}$ Department of Epidemiology, University of Michigan School of Public Health, Ann Arbor, Michigan

${ }^{2}$ Department of Environmental Health Sciences, University of Michigan School of Public Health, Ann Arbor, Michigan

${ }^{3}$ INCAP Research Center for the Prevention of Chronic Diseases, Guatemala City, Guatemala

${ }^{4}$ Center for Human Growth and Development University of Michigan, Ann Arbor, Michigan

\section{Correspondence}

K. Flannagan, Department of Epidemiology, University of Michigan School of Public Health, Room 4665 SPH I, 1415

Washington Heights, Ann Arbor, MI 48109.

Email: kflanna@umich.edu

Funding information

Funded by the United States

National Heart, Lung, and

Blood Institute, contract

BAA-NHLBI-HV-09-12.

\begin{abstract}
Objective: Telomere length is a biomarker of cumulative stress and inflammation related to chronic disease risk. We examined the associations of leukocyte telomere length (LTL) with sociodemographic and anthropometric variables and estimated LTL family aggregation in Central America, a region with a high burden of chronic disease where LTL has not been studied.

Methods: We conducted a cross-sectional study of 174 school age children and their parents in the capital cities of Belize, Honduras, Nicaragua, Costa Rica, Panama, and the city of Tuxtla-Gutierrez in Mexico. We measured LTL by quantitative PCR in DNA extracted from whole blood. We compared the distribution of LTL by categories of sociodemographic and anthropometric characteristics using linear regression. Family aggregation was estimated with correlation coefficients and intraclass correlations.
\end{abstract}

Results: In mothers, LTL was inversely associated with age $(P$, trend $<.0001)$ and positively associated with height $(P=.0002)$. Among fathers, LTL was inversely associated with food insecurity $(P$, trend $=.0004)$. In children, boys had $0.10 \log$ units shorter LTL than girls (95\% CI: $-0.17,-0.03 ; P=.004)$. LTL was inversely associated with parental education $(P$, trend $=.01)$ and positively associated with paternal age at birth $(P$, trend $<.0001)$, maternal LTL $(P$, trend $=.007)$, and paternal LTL $(P$, trend $=.02)$. LTL varied significantly by country of origin among all family members. Aggregation was greatest between children and their mothers, and mostly occurred at the country, rather than family, level.

Conclusion: LTL is associated with age and height in women; food insecurity in men; and sex, parental education, parental LTL, and paternal age at birth among children.

\section{1 | INTRODUCTION}

Telomeres are repeated DNA sequences at the ends of chromosomes. They protect chromosomes against loss of genomic DNA during replication and cell division, and prevent chromosome ends from fusing together (Blackburn,

Institution: University of Michigan School of Public Health, 1415 Washington Heights, Ann Arbor MI 48109-2029
2005). Every time a somatic cell divides, its telomeres undergo incomplete replication at the ends of DNA strands and, as a result, telomeres grow shorter over the lifetime of the cell (Blackburn, 2005; Starkweather et al., 2014). Leukocyte telomere length (LTL) in humans decreases with chronological age, inflammation, and damage to DNA from oxidative stress (Aviv, 2009). Hence, LTL could be a useful marker of biological aging and of risk for chronic diseases resulting from environment and lifestyle conditions that 
induce inflammation and oxidative stress (Aviv, 2009). Short LTL is associated with risk factors including chronic psychological stress (Epel et al., 2004; Næss \& Kirkengen, 2015), smoking (Valdes et al., 2005), and dietary exposures (Paul, 2011). The nature of the associations between LTL and chronic diseases is less clear. Some studies found associations between short LTL and risk of myocardial infarction, stroke (Fitzpatrick et al., 2007), type II diabetes (Salpea et al., 2010; Zhao, Miao, Wang, Ding, \& Wang, 2013), and cancer (Wentzensen, Mirabello, Pfeiffer, \& Savage, 2011). Other studies have found no association (Fernández-Alvira et al., 2016; Schürks, Prescott, Dushkes, De Vivo, \& Rexrode, 2013) or have only found associations in population subgroups (Needham et al., 2015; O'Donnell et al., 2008). A large meta-analysis (Haycock et al., 2014) found an inverse association between LTL and coronary heart disease, but the evidence for an association with cerebrovascular disease was less clear. The meaning of LTL as a biomarker of chronic disease risk is still uncertain.

Many studies have demonstrated links between telomere length and demographic, anthropometric, and socioeconomic characteristics. These studies have generally found that men (Gardner et al., 2014), people with obesity, (Müezzinler, Zaineddin, \& Brenner, 2014), and people of low socioeconomic status (Robertson et al., 2013) have comparatively short telomeres. However, with the exception of two studies from Costa Rica (Rehkopf et al., 2013, 2014), few investigations have been conducted in Latin American countries, and much of the existing literature may not be applicable to these populations. Because chronic illnesses, particularly cardiovascular diseases, are among the leading causes of death in this region (Rivera-Andrade \& Luna, 2014), examining the distribution of a novel marker for these conditions according to sociodemographic characteristics could inform the identification of high risk groups that may benefit from preventive measures. Furthermore, studying correlates of LTL in a new population with high rates of chronic disease may help to elucidate the relations between these diseases and LTL.

There is evidence that LTL is partly heritable (Broer et al., 2013), although the extent to which genetics and environment each influence LTL is unclear. Additionally, parental characteristics may influence LTL in children as early as in utero, infancy, and throughout childhood (Shalev et al., 2013). For these reasons, we studied LTL in children and their parents in a setting where this biomarker has not been thoroughly investigated.

The aim of this study was to examine family aggregation of LTL and the associations between LTL and demographic, anthropometric, and socioeconomic traits of school-age children and their parents from six Central American countries. We hypothesized that there would be LTL aggregation between children and each of their parents as a result of shared genetics and environment. There would be less aggregation between spouses as a result of shared environment in adulthood only. We hypothesized that age, male sex, higher BMI, and smoking would be associated with shorter LTL. Finally, we studied several indicators of socioeconomic status (SES) and predicted that lower SES would be associated with shorter LTL.

\section{2 | METHODS}

\subsection{Study design and population}

The Nine Mesoamerican Countries Metabolic Syndrome Study (NiMeCoMeS) has been described in detail elsewhere (Villamor, Finan, Ramirez-Zea, Roman, \& Nine Mesoamerican Countries Metabolic Syndrome Study, 2016). Briefly, we conducted a cross-sectional study of nutrition and cardiovascular health among school-age children and their parents in nine countries of the Mesoamerican region. We aimed to recruit 30 families from the capital cities of Belize, Guatemala, El Salvador, Honduras, Nicaragua, Costa Rica, Panama, and the Dominican Republic, and from the city of Tuxtla Gutiérrez in Chiapas, Mexico. Between July 2011 and November 2013 we identified 4-10 public primary schools in the periurban areas of each city, roughly representing the four cardinal directions. Study teams requested the list of enrolled students from each school and randomly selected approximately 80 children ages 7-12 years per country as potentially eligible for recruitment. They visited the schools and interviewed the children to confirm additional eligibility criteria, including living with both biological parents, not being pregnant or having a pregnant mother, and not having a sibling already invited to participate. Parents of potentially eligible families received a written invitation to attend a meeting, held at the school, in which the study aims and procedures were explained. At the end of this meeting, each family received a written informed consent form and was afforded 1 week to consider participation in the study. Signed consent forms were received at the schools and assent to participate was confirmed from the children by a research team member. The final number of enrolled families was 267 (Mexico, 31; Belize, 31; Guatemala, 31; El Salvador, 30; Honduras, 30; Nicaragua, 31; Costa Rica, 27; Panama, 26; and the Dominican Republic, 30).

The study protocol and procedures were approved by the Institutional Review Boards (IRB) of collaborating institutions in each of the nine countries and by the University of Michigan Health and Behavioral Sciences IRB.

\section{2 | Data collection}

Families who consented to participate received an appointment for a home visit by the research team, or for a visit to a 
health center if they preferred. Each family member was asked to fast for at least 6 hours before the visit. During these visits, each participant completed a questionnaire containing information on sociodemographic characteristics including age, education level, and socioeconomic status indicators; as well as health and dietary habits. The Latin American and Caribbean Food Security Scale (Pérez-Escamilla, MelgarQuiñonez, Nord, Álvarez, \& Segall-Correa, 2007) was administered to the mothers. The survey consists of 16 yesno questions regarding food insecurity experiences in the household during the previous 3 months and has been validated for use in this region.

At this same visit, investigators obtained anthropometric measurements including height, weight, and waist circumference. Height was measured without shoes to the nearest millimeter with the use of portable Seca stadiometers (Seca, Hamburg, Germany). Weight was measured in light clothing to the nearest $100 \mathrm{~g}$ with use of Tanita scales (Tanita, Tokyo, Japan). Waist circumference was measured at the end of an unforced exhalation with the use of a metric tape, accurate to the nearest millimeter. In adults, it was measured at the midpoint between the lowest border of the ribcage and the iliac crest, and in children it was measured above the uppermost lateral border of the right ilium. All measures were obtained in triplicate. At the end of the visit, researchers obtained biological samples from each participating family member. Approximately $7.5 \mathrm{~mL}$ of whole blood were collected in EDTA tubes and cryostored at $-20^{\circ} \mathrm{C}$ on the same day. The time until samples were frozen was the same for all countries. The samples were transported frozen from their respective countries to the Institute of Nutrition of Central America and Panama (INCAP) in Guatemala City, Guatemala, and from there were transported frozen to the University of Michigan for DNA extraction and analysis. Due to logistical constraints, samples for DNA extraction were only collected in participants from Belize, Honduras, Nicaragua, Costa Rica, Panama, and Mexico.

\subsection{DNA extraction and telomere length measurement by qPCR}

We extracted DNA from whole blood using a Qiagen Qiasymphony and QIAsymphony DSP DNA Midi Kits (Qiagen, Valencia, CA, USA). Because data collection was carried out through a 14 month span, storage time between collection and DNA extraction was longest for samples from participants in Honduras and Nicaragua, and shortest for samples from participants in Panama and Costa Rica. After DNA extraction, all LTL measurements were made within 2 months. We measured LTL using a monochrome multiplex qPCR procedure which has been described in detail elsewhere (Cawthon, 2009). Briefly, all qPCR reactions were carried out using $10 \mathrm{ng}$ of input DNA, $\mathrm{iQ}^{\mathrm{TM}}$ SYBR Green
Supermix (Bio-Rad Laboratories, Inc., Hercules, CA, USA), and two sets of primers (Invitrogen, Carlsbad, CA, USA, sequences described in (Cawthon, 2009)): telg/telc (to amplify telomeres) and albu/albd (to amplify albumin, a single-copy gene). The same batch of standard DNA (extracted from MCF-7 cells) was serially diluted to make two standard curves on each plate, one for telomeres and one for albumin, with seven points per curve (at concentrations of 291.6, 97.2, 32.4, $10.8,3.6,1.2$, and $0.4 \mathrm{ng} / \mu \mathrm{L}$ ). These curves were used to quantify the telomere $(\mathrm{T})$ and albumin (S) signals for each reaction, and LTL was calculated as the T/S ratio. This ratio gives a measurement of telomere length relative to that of the standard DNA, and is comparable for all samples measured against the same standard DNA. All samples were run in triplicate, and all plates included a positive control sample to assess inter-assay variation, as well as a no template control to detect spurious amplification. Intra-assay coefficients of variation (CV; calculated as the mean of all individual CVs from a given plate, where individual $\mathrm{CV}$ is calculated as the standard deviation among a set of T/S triplicates divided by the mean of those triplicates) for all plates were less than $16 \%$. Interassay CV (calculated as the standard deviation of all platespecific T/S means for the control sample divided by the mean of those means) was $37 \%$.

To further assess LTL measurement accuracy, we sent a random selection of 47 samples for testing at Dr. Elizabeth Blackburn's laboratory at the University of California, San Francisco. This laboratory has a well-established protocol for performing LTL measurement (Lin et al., 2010) and is widely considered to produce high-quality data. Their LTL measurements of samples from the National Health and Nutrition Examination Survey have been reviewed for quality by the Centers for Disease Control and Prevention and approved for public availability (Needham et al., 2015). The samples that we sent covered the entire range of $\mathrm{T} / \mathrm{S}$ ratios as measured at our laboratory. The agreement between our measurements and those from the Blackburn laboratory was excellent (Spearman correlation: 0.88 , intraclass correlation coefficient: 0.74).

\section{$2.4 \mid$ Definition of outcome and exposures}

The primary outcome was LTL. We calculated the median of the three LTL measurements for each participant (Villamor $\&$ Bosch, 2015) and log-transformed the variable to achieve normality. The primary exposures were sociodemographic and anthropometric variables: age, sex (for children), height, body mass index (BMI), country of origin, education level, parity, smoking status, monthly household income, and household food insecurity. We used the median of 3 replicate measures for each anthropometric indicator in the analyses (Villamor \& Bosch, 2015). Height was categorized into sexspecific quartiles for the adults. BMI was calculated as 
weight in $\mathrm{kg}$ divided by the square of height in meters. In adults, it was categorized as $<25,25-<30$, or $30+$ according to the World Health Organization (1995). A BMI $<18.5 \mathrm{~kg} / \mathrm{m}^{2}$ was not considered since there were very few adults under this cut point. In children, we estimated heightand BMI-for-sex-and-age Z-scores according to the World Health Organization growth references (de Onis, 2007). Parental education level was categorized according to the number of completed school years (incomplete elementary, 1-5 years; complete elementary, 6 years; incomplete secondary, 7-11 years; complete secondary, 12 years; and postsecondary, $\geq 13$ years). Smoking status was classified as never/ever in adults. For children, passive smoking was defined as any known smoke exposure from a parent during the child's lifetime vs. none. We divided household income into country-specific tertiles of low, medium, and high. A household food insecurity score was created as the sum of all affirmative answers to the survey and categorized as none (0), mild (1-5), moderate (6-10), or severe (11-16). For the analysis of LTL among children, we also considered maternal and paternal LTL as exposure variables, categorized into sex-specific quartiles.

\section{5 | Statistical analysis}

We conducted separate analyses for mothers, fathers, and children because telomere length dynamics vary by age and sex (Starkweather et al., 2014). We first compared the distribution of log LTL across categories of the sociodemographic and anthropometric correlates by estimating the mean log LTL. For ordinal variables, we estimated tests for linear trend with the use of linear regression models in which a variable representing ordinal categories of the characteristic was introduced as a continuous covariate. For nominal variables, we conducted $\chi^{2}$ score tests. We tested for interaction by sex by including cross-product terms between sex and each sociodemographic predictor. Because we chose sociodemographic covariates based on existing literature and with a priori hypotheses, we did not adjust for multiple comparisons (Perneger, 1998). Next, we estimated adjusted differences and 95\% confidence intervals in mean log LTL by categories of predictors from multivariable linear regression models. These models included as covariates those correlates that were significantly associated with $\log$ LTL at $P<.05$, or that were considered relevant from a mechanistic viewpoint. One multivariable model was fitted separately for each family member. For men, the model included age, food security, and country of origin. The model for women included age, height, and country of origin. For children, the model included age, sex, highest parental educational attainment, maternal and paternal LTL, father's age at child's birth, and country of origin. Although age was not statistically significantly associated with LTL in men or children, we kept it in the models because age is a well-known predictor of LTL. All models were fitted using generalized estimating equations with empirical standard errors, which are robust to heteroskedasticity and non-normality (White, 1980). We also conducted supplemental analyses using untransformed LTL as the outcome.

To examine family aggregation, we calculated Pearson correlations of $\log$ LTL between children and each parent, and between mothers and fathers. Using a mixed effects model of $\log$ LTL with random intercepts for country and family, and fixed effects for age and sex, we calculated adjusted intraclass correlation coefficients (ICC). The ICC indicates the proportion of the total variance in LTL that is explained by variance between clusters at each level (country of origin and family nested within country). A high ICC would imply that persons randomly selected from the same country or the same family are likely to have similar LTL.

We conducted all analyses using Statistical Analysis Software version 9.4 (SAS Institute, Cary, NC, USA).

\section{3 | RESULTS}

The analytic sample comprised all participants from the six countries from whom whole blood was available. Samples were available from 174 mothers, 172 fathers, and 164 children. Among adults, $50.3 \%$ were women. The mean $( \pm$ SD) age was $37.0 \pm 6.4$ years for women and $40.4 \pm 8.4$ years for men. Among children, the mean $( \pm \mathrm{SD})$ age was $9.9 \pm 1.7$ years and $52.4 \%$ were female. Mean $( \pm$ SD) LTL in mothers, fathers, and children was $2.27 \pm 0.86$ (log mean $0.76 \pm 0.36), \quad 2.14 \pm 0.74 \quad(\log$ mean $0.70 \pm 0.34)$, and $3.35 \pm 1.07$ (log mean $1.16 \pm 0.33)$, respectively.

\section{1 | Women's LTL}

In bivariate analysis, mothers' LTL was inversely associated with age and parity and positively associated with height (Table 1). The lowest values were in women from Belize and Honduras, and the highest in Mexican, Panamanian, and Costa Rican women.

In multivariable analysis (Table 2), mothers aged 45+ years had a $0.33 \log$ units shorter mean LTL than did mothers younger than 30 years of age $(P=.0008)$, and women from Mexico had a mean LTL 0.41 log units longer than did women from Belize $(P<.0001)$. Mean LTL in the lowest height quartile was $0.18 \log$ units significantly shorter than that in quartiles 2,3 , and 4 combined $(95 \% \mathrm{CI}:-0.28$, $-0.09 ; P=.0002)$. BMI, smoking status, education level, household income, household food insecurity, and parity were not significantly associated with LTL after adjustment. The within-country associations of age and LTL were all inverse; the strongest associations were in Panama and Costa 
TABLE 1 Mean ( \pm SD) log LTL according to categories of sociodemographic characteristics in adults from Mesoamerica

\begin{tabular}{|c|c|c|c|c|}
\hline \multirow[b]{2}{*}{ Characteristics } & \multicolumn{2}{|c|}{ Mothers } & \multicolumn{2}{|c|}{ Fathers } \\
\hline & $\mathbf{N}$ & $\begin{array}{l}\text { Unadjusted mean } \\
\log \text { LTL } \pm \text { SD }\end{array}$ & $\mathbf{N}$ & $\begin{array}{l}\text { Unadjusted mean } \\
\log \mathrm{LTL} \pm \mathrm{SD}\end{array}$ \\
\hline Overall & 174 & $0.76 \pm 0.36$ & 172 & $0.70 \pm 0.34$ \\
\hline \multicolumn{5}{|l|}{ Age (years) } \\
\hline$<30$ & 27 & $0.86 \pm 0.39$ & 12 & $0.75 \pm 0.34$ \\
\hline 30 to $<35$ & 33 & $0.89 \pm 0.34$ & 35 & $0.70 \pm 0.35$ \\
\hline 35 to $<40$ & 63 & $0.74 \pm 0.35$ & 51 & $0.69 \pm 0.38$ \\
\hline 40 to $<45$ & 34 & $0.69 \pm 0.34$ & 35 & $0.69 \pm 0.35$ \\
\hline $45+$ & 17 & $0.52 \pm 0.33$ & 39 & $0.70 \pm 0.30$ \\
\hline$P$, trend $^{\mathrm{a}}$ & & .0002 & & .74 \\
\hline$P$, interaction $^{\mathrm{b}}$ & & & & \\
\hline \multicolumn{5}{|c|}{ Height quartile (sex-specific medians, cm) } \\
\hline Q1 (mothers $=149.1$, fathers $=159.3$ ) & 43 & $0.58 \pm 0.37$ & 42 & $0.71 \pm 0.36$ \\
\hline Q2 (mothers $=153.8$, fathers $=165.3$ ) & 43 & $0.84 \pm 0.34$ & 44 & $0.70 \pm 0.28$ \\
\hline Q3 (mothers $=157.2$, fathers $=169.8$ ) & 45 & $0.82 \pm 0.31$ & 43 & $0.69 \pm 0.35$ \\
\hline Q4 (mothers $=163.2$, fathers $=176.9)$ & 43 & $0.77 \pm 0.38$ & 43 & $0.71 \pm 0.39$ \\
\hline$P$, trend & & .03 & & .90 \\
\hline$P$, interaction & .07 & & & \\
\hline \multicolumn{5}{|l|}{ BMI $\left(\mathrm{kg} / \mathrm{m}^{2}\right)$} \\
\hline$<25$ & 30 & $0.82 \pm 0.43$ & 33 & $0.80 \pm 0.32$ \\
\hline 25 to $<30$ & 65 & $0.71 \pm 0.38$ & 87 & $0.69 \pm 0.32$ \\
\hline $30+$ & 79 & $0.76 \pm 0.32$ & 52 & $0.66 \pm 0.40$ \\
\hline$P$, trend & & .71 & & .10 \\
\hline$P$, interaction & .48 & & & \\
\hline
\end{tabular}

\section{Education level}

\begin{tabular}{lllll} 
Incomplete elementary & 25 & $0.58 \pm 0.34$ & 14 & $0.74 \pm 0.45$ \\
Complete elementary & 24 & $0.82 \pm 0.32$ & 27 & $0.64 \pm 0.39$ \\
\hline Incomplete secondary & 50 & $0.83 \pm 0.32$ & 51 & $0.69 \pm 0.37$ \\
Complete secondary & 31 & $0.73 \pm 0.43$ & 26 & $0.69 \pm 0.28$ \\
Post secondary & 40 & $0.75 \pm 0.36$ & 51 & $0.75 \pm 0.28$ \\
$P$, trend & & .32 & & .44 \\
$P$, interaction & .37 & & & (continues)
\end{tabular}


TABLE 1 (continues)

\begin{tabular}{|c|c|c|c|c|}
\hline \multirow[b]{2}{*}{ Characteristics } & \multicolumn{2}{|c|}{ Mothers } & \multicolumn{2}{|c|}{ Fathers } \\
\hline & $\mathbf{N}$ & $\begin{array}{l}\text { Unadjusted mean } \\
\log \mathrm{LTL} \pm \mathrm{SD}\end{array}$ & $\mathbf{N}$ & $\begin{array}{l}\text { Unadjusted mean } \\
\log \mathrm{LTL} \pm \mathrm{SD}\end{array}$ \\
\hline \multicolumn{5}{|l|}{ Parity } \\
\hline 1 & 16 & $0.88 \pm 0.39$ & & \\
\hline 2 & 56 & $0.79 \pm 0.35$ & & \\
\hline 3 & 60 & $0.75 \pm 0.37$ & & \\
\hline $4+$ & 41 & $0.67 \pm 0.35$ & & \\
\hline$P$, trend & & .03 & & \\
\hline
\end{tabular}

\section{Smoking status}

$\begin{array}{lllll}\text { Never smoked } & 138 & 0.75 \pm 0.36 & 70 & 0.74 \pm 0.33 \\ \text { Ever smoked } & 36 & 0.76 \pm 0.36 & 101 & 0.68 \pm 0.35 \\ P^{\mathrm{c}} & & .96 & & .22\end{array}$

$P$, interaction

.59

Household income level, adjusted for country

Low
Medium
High
$P$, trend
$P$, interaction

$\begin{array}{llll}31 & 0.86 \pm 0.37 & 31 & 0.75 \pm 0.38 \\ 71 & 0.68 \pm 0.37 & 69 & 0.68 \pm 0.33 \\ 69 & 0.78 \pm 0.35 & 69 & 0.70 \pm 0.35\end{array}$

Food security

\begin{tabular}{|c|c|c|c|c|}
\hline No insecurity & 74 & $0.75 \pm 0.37$ & 74 & $0.79 \pm 0.27$ \\
\hline Mild insecurity & 44 & $0.81 \pm 0.35$ & 44 & $0.73 \pm 0.37$ \\
\hline Moderate insecurity & 37 & $0.64 \pm 0.39$ & 35 & $0.64 \pm 0.39$ \\
\hline Severe insecurity & 19 & $0.88 \pm 0.27$ & 19 & $0.40 \pm 0.28$ \\
\hline$P$, trend & & .84 & & $<.0001$ \\
\hline$P$, interaction & \multicolumn{4}{|c|}{.009} \\
\hline \multicolumn{5}{|l|}{ Country of origin } \\
\hline Belize & 29 & $0.50 \pm 0.28$ & 28 & $0.81 \pm 0.40$ \\
\hline Honduras & 30 & $0.55 \pm 0.42$ & 29 & $0.78 \pm 0.24$ \\
\hline Nicaragua & 31 & $0.83 \pm 0.27$ & 31 & $0.43 \pm 0.35$ \\
\hline Costa Rica & 27 & $0.87 \pm 0.30$ & 27 & $0.82 \pm 0.30$ \\
\hline Panama & 26 & $0.89 \pm 0.37$ & 26 & $0.72 \pm 0.37$ \\
\hline Mexico & 31 & $0.91 \pm 0.29$ & 31 & $0.68 \pm 0.26$ \\
\hline$P$ & & $<.0001$ & & .001 \\
\hline$P$, interaction & & & & \\
\hline
\end{tabular}

${ }^{\mathrm{a}}$ From linear regression models with log LTL as the outcome and a variable representing ordinal categories of the characteristic introduced as a continuous predictor.

${ }^{\mathrm{b}}$ From a $\chi^{2}$ score test for the cross-product term of interaction between sex and the sociodemographic predictor.

${ }^{\mathrm{c}}$ From a $\chi^{2}$ score test. 
Rica, and the weakest in Nicaragua (Supporting Information Figure S1).

\section{2 | Men's LTL}

Among fathers, food insecurity was inversely associated with LTL in bivariate analyses (Table 1). Men from Costa Rica, Belize, and Honduras had the longest LTL while men from Nicaragua and Mexico had the shortest. In multivariable analysis (Table 2), men from households with severe food insecurity had a mean log LTL 0.29 units shorter than did men from food secure households $(P=.0002)$. Fathers from Belize had a mean log LTL 0.35 units longer than did fathers from Nicaragua $(P=.0004)$. Height, BMI, smoking status, education level, and household income were not associated with LTL. Age was also not significantly associated with LTL, but was retained in the adjusted model because of its known influence on this biomarker. When stratified by country, the age-LTL associations were mainly parallel and slightly inverse; there was a slight positive association in men from Panama and a stronger inverse association in men from Honduras (Supporting Information Figure S1).

TABLE 2 Adjusted differences in log LTL according to categories of sociodemographic characteristics in adults from Mesoamerica

\begin{tabular}{|c|c|c|c|c|}
\hline \multirow[b]{2}{*}{ Characteristics } & \multicolumn{2}{|l|}{ Mothers } & \multicolumn{2}{|l|}{ Fathers } \\
\hline & $\begin{array}{l}\text { Adjusted } \\
\text { difference }\end{array}$ & $(95 \% \mathrm{CI})^{\mathrm{a}}$ & $\begin{array}{l}\text { Adjusted } \\
\text { difference }\end{array}$ & $(95 \% \mathrm{CI})^{\mathrm{b}}$ \\
\hline \multicolumn{5}{|l|}{ Age (years) } \\
\hline$<30$ & Reference & & Reference & \\
\hline 30 to $<35$ & -0.03 & $(-0.20,0.14)$ & 0.06 & $(-0.17,0.29)$ \\
\hline 35 to $<40$ & -0.17 & $(-0.32,-0.02)$ & -0.10 & $(-0.32,0.13)$ \\
\hline 40 to $<45$ & -0.23 & $(-0.39,-0.07)$ & -0.15 & $(-0.39,0.09)$ \\
\hline $45+$ & -0.33 & $(-0.52,-0.14)$ & -0.08 & $(-0.31,0.16)$ \\
\hline$P$, trend $^{\mathrm{c}}$ & $<.0001$ & & .08 & \\
\hline$P$, interaction $^{\mathrm{d}}$ & & & & \\
\hline
\end{tabular}

\section{Mother's height (cm)}

$\begin{array}{lll}140.6-151.9 & \text { Reference } & \\ 152.0-155.7 & 0.22 & (0.10,0.33) \\ 155.8-159.2 & 0.20 & (0.07,0.32) \\ 159.3-181.9 & 0.12 & (0.00,0.24) \\ P, \text { trend } & .11 & \\ P, \text { interaction } & & \end{array}$

Food security

No insecurity

Reference

Mild insecurity

$-0.05$

$(-0.18,0.08)$

Moderate insecurity

$-0.14$

$(-0.28,-0.01)$

Severe insecurity

$-0.29$

$(-0.44,-0.14)$

$P$, trend

.0004

$P$, interaction

.05 
TABLE 2 (continues)

\begin{tabular}{|c|c|c|c|c|}
\hline \multirow[b]{2}{*}{ Characteristics } & \multicolumn{2}{|l|}{ Mothers } & \multicolumn{2}{|l|}{ Fathers } \\
\hline & $\begin{array}{l}\text { Adjusted } \\
\text { difference }\end{array}$ & $(95 \% \mathrm{CI})^{\mathrm{a}}$ & $\begin{array}{l}\text { Adjusted } \\
\text { difference }\end{array}$ & $(95 \% \mathrm{CI})^{\mathrm{b}}$ \\
\hline \multicolumn{5}{|c|}{ Country of origin } \\
\hline Belize & Reference & & Reference & \\
\hline Honduras & 0.04 & $(-0.12,0.21)$ & -0.04 & $(-0.22,0.13)$ \\
\hline Nicaragua & 0.24 & $(0.11,0.38)$ & -0.35 & $(-0.54,-0.16)$ \\
\hline Costa Rica & 0.33 & $(0.19,0.48)$ & -0.03 & $(-0.21,0.15)$ \\
\hline Panama & 0.34 & $(0.18,0.50)$ & -0.10 & $(-0.30,0.10)$ \\
\hline Mexico & 0.41 & $(0.27,0.54)$ & -0.20 & $(-0.36,-0.03)$ \\
\hline$P^{\mathrm{e}}$ & $<.0001$ & & .004 & \\
\hline$P$, interaction & & & & \\
\hline
\end{tabular}

${ }^{\mathrm{a}}$ From a linear regression model adjusted for age, height, and country of origin.

${ }^{\mathrm{b}}$ From a linear regression model adjusted for age, food insecurity, and country of origin.

${ }^{c}$ From linear regression models with $\log$ LTL as the outcome and a variable representing ordinal categories of the characteristic introduced as a continuous predictor.

${ }^{\mathrm{d}}$ From a $\chi^{2}$ score test for the cross-product term of interaction between sex and the sociodemographic predictor.

${ }^{\mathrm{e}}$ From a $\chi^{2}$ score test.

\section{$3.3 \mid$ Children's LTL}

In bivariate analysis, children's LTL was inversely associated with male sex and the parents' highest education level and positively associated with maternal telomere length (Table 3). The longest mean log LTL was among children from Panama and Mexico and the shortest in children from Honduras $(P<.0001)$. In multivariable analysis, boys had a $0.10 \log$ units shorter LTL than girls $(P=.005)$. Children in households with at least one parent with a postsecondary education had a mean LTL $0.13 \log$ units shorter than children whose parents only had incomplete elementary schooling $(P=.04)$. Further adjustment for BMI-forage $\mathrm{Z}$ score did not change the association with parental education level. Telomere lengths of both parents were positively associated with the children's LTL; the association was stronger with the mothers' LTL. Paternal age at child's birth was also positively associated with LTL after adjustment. Mean LTL among children born to fathers $\geq 40$ years of age was $0.27 \mathrm{log}$ units longer than mean LTL in children whose fathers were less than 25 years old $(P=.0001)$. Children from Panama had a mean LTL 0.61 $\log$ units longer than children from Honduras $(P<.0001)$. Children's LTL was not significantly associated with mother's parity, parental smoking, or parental anthropometry (data available on request). It was also not associated with children's age, height-for-age, BMI-for-age, household income, household food insecurity, or the mother's age at the child's birth.

\section{4 $\mid$ Aggregation}

Children's log LTL was significantly positively correlated with their mothers' (Pearson's $R=0.27, P=.0004$ ) and was not correlated with their fathers' (Pearson's $R=0.004, P=.96$ ) (Table 4). Mothers' and fathers' $\log$ LTL were weakly, inversely correlated (Pearson's $R=-0.19, P=.01$ ). Similarly, the age- and sex-adjusted ICCs were highest for mothers and children only (country-level ICC $=28.8 \%$, family-level ICC $=32.1 \%$ ). ICCs were nearly identical for the whole family (country- and familylevel ICC $=10.5 \%$ ) and for fathers and children only (countryand family-level ICC $=10.7 \%$ ). In all cases, the family-level ICC was either identical to or only minimally larger than the country-level ICC.

All results from supplemental analyses using untransformed LTL were similar to results using log LTL (Supporting Information Tables S1-S4).

\section{4 | DISCUSSION}

In this cross-sectional study of families from Mesoamerica, longer LTL was associated with younger age and height in women; and with food security in men. In children, longer LTL was associated with female sex, lower parental 
TAB LE 3 Mean ( \pm SD) and differences in log LTL according to categories of sociodemographic characteristics in children from Mesoamerica

\begin{tabular}{lllll} 
Characteristics & $\mathbf{N}$ & $\begin{array}{l}\text { Unadjusted mean } \\
\mathbf{l o g} \mathbf{L T L} \pm \mathbf{S D}\end{array}$ & $\begin{array}{l}\text { Adjusted } \\
\text { difference }\end{array}$ & $\mathbf{( 9 5 \% ~ C I ) ~}^{\mathbf{a}}$ \\
\hline Overall & 164 & $1.16 \pm 0.33$ & & \\
\hline Age (years) & 58 & $1.14 \pm 0.36$ & Reference & \\
$<9$ & 53 & $1.14 \pm 0.30$ & 0.02 & $(-0.06,0.10)$ \\
\hline to $<11$ & 53 & $1.19 \pm 0.32$ & 0.03 & $(-0.05,0.12)$ \\
\hline $11+$ & & .45 & .46 & \\
\hline$P$, trend & & & & \\
\hline Sex & 86 & $1.20 \pm 0.34$ & Reference & $(-0.17,-0.03)$ \\
\hline Female & 78 & $1.11 \pm 0.31$ & -0.10 & \\
\hline Male & & 0.08 & 0.005 & \\
\hline$P^{c}$ & & & &
\end{tabular}

Height-for-age Z score

$\begin{array}{lll}<-1 & 36 & 1.20 \pm 0.30 \\ -1 \text { to }<0 & 58 & 1.11 \pm 0.34 \\ 0 \text { to }<1 & 45 & 1.19 \pm 0.34 \\ 1+ & 25 & 1.15 \pm 0.34 \\ P, \text { trend } & & .98\end{array}$

BMI-for-age $\mathbf{Z}$ score

$\begin{array}{lll}<-1 & 23 & 1.08 \pm 0.32 \\ -1 \text { to }<0 & 36 & 1.15 \pm 0.37 \\ 0 \text { to }<1 & 46 & 1.20 \pm 0.32 \\ 1+ & 59 & 1.15 \pm 0.31 \\ P, \text { trend } & & .39\end{array}$

Highest parental educational attainment

\begin{tabular}{lllll} 
Incomplete elementary & 13 & $1.24 \pm 0.23$ & Reference & \\
Complete elementary & 16 & $1.26 \pm 0.32$ & -0.01 & $(-0.16,0.13)$ \\
\hline Incomplete secondary & 45 & $1.24 \pm 0.24$ & -0.06 & $(-0.20,0.08)$ \\
Complete secondary & 28 & $1.03 \pm 0.37$ & -0.15 & $(-0.30,0.00)$ \\
Post secondary & 62 & $1.11 \pm 0.36$ & -0.13 & $(-0.26,-0.01)$ \\
$P$, trend & & .006 & .01 & (continues)
\end{tabular}


TABLE 3 (continues)

\begin{tabular}{|c|c|c|c|c|}
\hline Characteristics & $\mathbf{N}$ & $\begin{array}{l}\text { Unadjusted mean } \\
\log \mathrm{LTL} \pm \mathrm{SD}\end{array}$ & $\begin{array}{l}\text { Adjusted } \\
\text { difference }\end{array}$ & $(95 \% \mathrm{CI})^{\mathrm{a}}$ \\
\hline \multicolumn{5}{|c|}{ Household income level, adjusted for country } \\
\hline Low & 29 & $1.29 \pm 0.35$ & & \\
\hline Medium & 68 & $1.09 \pm 0.32$ & & \\
\hline High & 63 & $1.18 \pm 0.30$ & & \\
\hline$P$, trend & & .42 & & \\
\hline \multicolumn{5}{|l|}{ Food insecurity } \\
\hline No insecurity & 72 & $1.16 \pm 0.32$ & & \\
\hline Mild insecurity & 41 & $1.11 \pm 0.35$ & & \\
\hline Moderate insecurity & 33 & $1.18 \pm 0.34$ & & \\
\hline Severe insecurity & 18 & $1.19 \pm 0.33$ & & \\
\hline$P$, trend & & .75 & & \\
\hline
\end{tabular}

\section{Maternal age at child's birth}

\begin{tabular}{|lll|}
$<20$ & 18 & $1.15 \pm 0.31$ \\
\hline 20 to $<25$ & 34 & $1.15 \pm 0.32$ \\
\hline 25 to $<30$ & 63 & $1.15 \pm 0.31$ \\
\hline 30 to $<35$ & 31 & $1.13 \pm 0.38$ \\
$35+$ & 18 & $1.24 \pm 0.36$ \\
$P$, trend & & .57
\end{tabular}

\section{Maternal telomere length}

$\begin{array}{lcccc}\text { Q1 } & 40 & 1.00 \pm 0.30 & \text { Reference } & (-0.06,0.14) \\ \text { Q2 } & 41 & 1.17 \pm 0.33 & 0.04 & (-0.04,0.15) \\ \text { Q3 } & 41 & 1.19 \pm 0.30 & 0.06 & (0.04,0.25) \\ \text { Q4 } & 40 & 1.27 \pm 0.33 & 0.15 & .007\end{array}$

\section{Paternal age at child's birth}

\begin{tabular}{lllll}
$<25$ & 42 & $1.13 \pm 0.29$ & Reference & $(-0.02,0.22)$ \\
\hline 25 to $<30$ & 46 & $1.16 \pm 0.36$ & 0.10 & $(0.03,0.24)$ \\
30 to $<35$ & 35 & $1.11 \pm 0.30$ & 0.13 & $(0.02,0.27)$ \\
35 to $<40$ & 20 & $1.23 \pm 0.29$ & 0.27 & $(0.13,0.41)$ \\
$40+$ & 21 & $1.21 \pm 0.42$ & $<.0001$ & \\
$P$ trend & & .29 &
\end{tabular}


TABLE 3 (continues)

\begin{tabular}{|c|c|c|c|c|}
\hline Characteristics & $\mathbf{N}$ & $\begin{array}{l}\text { Unadjusted mean } \\
\log \mathrm{LTL} \pm \mathrm{SD}\end{array}$ & $\begin{array}{l}\text { Adjusted } \\
\text { difference }\end{array}$ & $(95 \% \mathrm{CI})^{\mathrm{a}}$ \\
\hline \multicolumn{5}{|c|}{ Paternal telomere length } \\
\hline Q1 & 40 & $1.22 \pm 0.27$ & Reference & \\
\hline Q2 & 40 & $1.05 \pm 0.37$ & -0.02 & $(-0.13,0.08)$ \\
\hline Q3 & 41 & $1.18 \pm 0.36$ & 0.10 & $(-0.01,0.21)$ \\
\hline Q4 & 40 & $1.19 \pm 0.27$ & 0.09 & $(-0.02,0.20)$ \\
\hline$P$, trend & & .82 & .02 & \\
\hline \multicolumn{5}{|c|}{ Country of origin } \\
\hline Belize & 27 & $1.17 \pm 0.21$ & 0.42 & $(0.29,0.54)$ \\
\hline Honduras & 28 & $0.69 \pm 0.21$ & Reference & \\
\hline Nicaragua & 31 & $1.24 \pm 0.32$ & 0.53 & $(0.38,0.69)$ \\
\hline Costa Rica & 25 & $1.22 \pm 0.24$ & 0.42 & $(0.30,0.55)$ \\
\hline Panama & 25 & $1.33 \pm 0.28$ & 0.61 & $(0.48,0.73)$ \\
\hline Mexico & 28 & $1.31 \pm 0.22$ & 0.54 & $(0.44,0.65)$ \\
\hline$P$ & & $<.0001$ & $<.0001$ & \\
\hline
\end{tabular}

${ }^{\text {a}}$ From a linear regression model adjusted for age, sex, parents' highest education level, paternal age at child's birth, maternal and paternal telomere length, and country of origin.

${ }^{b}$ From linear regression models with $\log$ LTL as the outcome and a variable representing ordinal categories of the characteristic introduced as a continuous predictor.

${ }^{c}$ From a $\chi^{2}$ score test.

education level, parental LTL, and paternal age at child's birth. LTL differed significantly by country of origin in each group.

Shorter LTL can serve as a biomarker of biological aging and chronic disease risk (Starkweather et al., 2014). We found an inverse, monotonic relation between age and LTL in women only. This is unexpected, since most studies have found that age is inversely associated with LTL in both sexes (Müezzinler et al., 2014). Because measurement procedures were identical for all study participants, differential measurement error should not explain this finding. Differences in the direction and strength of the age-LTL association between men and women might be related to the age distribution of the study populations, since LTL attrition rates vary

TAB LE 4 Family correlations and intraclass correlation coefficients of log LTL

\begin{tabular}{|c|c|c|c|c|}
\hline & All & $\begin{array}{l}\text { Mothers and } \\
\text { children }\end{array}$ & $\begin{array}{l}\text { Fathers and } \\
\text { children }\end{array}$ & $\begin{array}{l}\text { Mothers and } \\
\text { fathers }\end{array}$ \\
\hline Correlation $^{\mathrm{a}}$ & - & 0.27 & 0.004 & -0.19 \\
\hline \multicolumn{5}{|l|}{$\operatorname{ICC}^{\mathrm{b}}(\%)$} \\
\hline Country-level & 10.5 & 28.8 & 10.7 & 6.1 \\
\hline Family-level & 10.5 & 32.1 & 10.7 & 6.1 \\
\hline
\end{tabular}

${ }^{\mathrm{a}}$ Pearson product-moment correlation.

${ }^{b}$ From a linear mixed model with random intercepts for country and family, and fixed effects for sex and age. ICCs calculated as either the variance of country-specific intercepts (for country-level ICC) or the sum of variances of country- and family-specific intercepts (for family-level ICC) divided by the sum of all variance components. 
differently by sex across the lifespan (Dalgård et al., 2015; Iwama et al., 1998). The lack of an association between age and LTL in children could be explained by the relatively narrow age range of children in our study.

We found that food insecurity in fathers was related to shorter LTL. This association had not been reported in other populations. It could be the result of life stress associated with an inability to consistently secure adequate food (Epel et al., 2004; Liu, Njai, Greenlund, Chapman, \& Croft, 2014), or from specific dietary deficiencies that could affect LTL (Paul, 2011). For example, intake patterns typical of households with food insecurity, including low intake of vegetables, legumes, and nuts (Tarasuk, 2001; Weigel \& Armijos, 2015), have been associated with shorter telomere length in previous studies (Lee, Jun, Yoon, Shin, \& Baik, 2015). It is uncertain why the association between food insecurity and LTL was restricted to fathers. Household food insecurity may have different consequences for fathers, mothers, and children. For example, fathers might experience more psychological stress associated with food insecurity than do mothers or children. Food insecurity could be acting as a proxy measure for aspects of SES such as occupational status that affect fathers differently than they do mothers or children. Alternatively, fathers' diets may be affected differently than other family members' by food insecurity. It is also possible that the association seen in fathers is spurious.

Children's LTL was inversely associated with parental education. Our findings are in agreement with one previous study of adults from six cities in the United States that found an inverse association of LTL with fathers' educational attainment among Hispanic study participants (Carroll, DiezRoux, Adler, \& Seeman, 2013). One possible explanation of the inverse association observed in our study could be related to the nutrition transition that these countries are undergoing. Through this transition, the burden of nutrition-related chronic diseases and their risk factors progressively shifts from people of higher SES to those living in poorer conditions, as countries undergo economic development. This transition tends to affect women before men. Countries in Central America are at a relatively early stage of the transition considering that the prevalence of chronic disease risk factors is higher in men of lower SES and women and children of higher SES (Villamor et al., 2016). Some obesogenic dietary factors that are typically consumed by children of higher SES (Nettleton, Diez-Roux, Jenny, Fitzpatrick, \& Jacobs, 2008) are predictors of short telomere length. One could hypothesize that an effect of parental education on LTL could be mediated through obesity. Adjusting for children's BMI did not change the association of parental education with LTL. However, this is a crude means of assessing mediation. In addition, BMI may not adequately capture all of the relevant consequences of the nutrition transition. We cannot rule out that LTL in children may be an indicator of adherence to unhealthy dietary or other lifestyles among the better-off. In contrast with the findings among children, education level was not associated with LTL in adults. It is possible that the education level of adults does not represent the same SES construct to them as parental education level does to children.

In our study, women in the shortest quartile of height had significantly shorter LTL than did taller women. Two previous studies examined the relation between adult height and telomere length, and both found no association (Cui et al., 2013; Pearce et al., 2012). One potential explanation for this discrepancy is that an association between height and LTL may exist only when comparing people of very short stature with taller ones. In the previous investigations women were not as short as those in our study. Very short final height in Mesoamerica is the consequence of stunting during childhood, which is attributable mainly to dietary deficiencies, a high burden of infection, and low SES (Silventoinen, 2003; Steckel, 2009; Subramanian, Özaltin, \& Finlay, 2011). Experiments in mice have shown that chronic infection leads to shortened LTL (Ilmonen, Kotrschal, \& Penn, 2008). It is possible that some of the determinants of short stature could also impair LTL.

We found that country was a strong predictor of LTL in adults and children. This finding is novel for Mesoamerica. One other study of inter-country variation examined average telomere length among men of similar age from 11 European countries and found a three-fold difference in mean LTL between the countries with highest and lowest means (Eisenberg et al., 2011). Although it is likely that our findings arose to some extent from true differences in LTL by country, it is also of note that timing of blood collection varied significantly across months of the year, and that month of collection was highly collinear with country. This is important because a study of LTL in Costa Rica found significant variation by the month in which LTL was measured (Rehkopf et al., 2014). There are other reasons to explain the association between country and LTL. It may reflect differences in lifestyle characteristics or ecological exposures that were not captured by the individual level variables we measured in the study. For example, LTL could be affected by stress associated with political and social unrest and conflict that took place in Nicaragua from the late 1970s through 1990s or in Chiapas, Mexico in the 1990s, by national health and social welfare policies, or by differences in standards of living between countries of different income levels.

In this population, the association between maternal and child LTL was stronger than the association between paternal and child LTL. This was consistent when comparing average LTL of children across quartiles of their parents' LTL, and when estimating the correlations and ICCs of LTL between children and each parent. The stronger association of child 
LTL with maternal, rather than paternal, LTL is in agreement with results from a large meta-analysis of six European and Australian cohorts (Broer et al., 2013) but contrary to studies in Swedish and Amish populations (Njajou et al., 2007; Nordfjäll, Svenson, Norrback, Adolfsson, \& Roos, 2009). Variation across studies could be the result of differences in parenting techniques and behaviors between countries.

LTL was weakly, inversely correlated between mothers and fathers. This finding differs from the six cohorts metaanalysis which showed a positive correlation between spouses' LTL (Broer et al., 2013). The inverse correlation may be driven by the opposite associations of country and LTL in men and women. Alternatively, men in Mesoamerica may be buffering their partners from the influence of some environmental predictors of LTL.

There were little differences between the ICCs at country and family levels for any configuration of family members. This indicates that family membership does not explain additional variance in LTL, conditional on age and sex, beyond what is explained by country of origin. In other words, members of the same family are no more likely to have similar LTL than persons from the same country. Since influences on LTL that operate at the country level are most likely nongenetic, this implies that environmental and lifestyle factors are important determinants of LTL in these populations.

Our study has many strengths. First, it provides new information on telomere length in countries where this biomarker has not been studied before. Second, because we collected data on parents and children within the same households, we were able to study associations between children's LTL and their parents' characteristics. Third, we had an opportunity to examine associations controlling for important confounders. Also, the measure of LTL had high external validity considering the high correlations with measures obtained at a reference laboratory. Finally, LTL was associated with many factors in the direction expected according to previous studies.

There are also some limitations. The cross-sectional nature of the design prevents making causal inferences. Also, the sample sizes within each country were small and we lacked samples from some of the countries originally included in the study. This prevented us from conducting country-specific analyses. The inter-assay CV for our LTL measurements was high. This could indicate a high degree of random measurement error of LTL in our study. Random error in a continuous outcome would not have biased the mean differences in LTL by categories of the exposures, but could have lowered the precision of the estimates and reduced the statistical power to detect associations.

In conclusion, we found that LTL is associated with age and height in women; food insecurity in men; and sex, parental education, parental LTL, and paternal age at birth among children. There are important between-country differ- ences in LTL, and little additional between-family variation. Children's LTL is more similar to their mothers' than their fathers'. Further studies are needed to assess the specific nature of these relations, particularly whether diet and other lifestyle characteristics explain a potential effect of household food insecurity and parental educational attainment on telomere length.

\section{ACKNOWLEDGMENTS}

The study was funded by the United States National Heart, Lung, and Blood Institute, contract BAA-NHLBI-HV-09-12.

Participants in the Nine Mesoamerican Countries Metabolic Syndrome Study (NiMeCoMeS) Group:

Mexico: Erika Lopez, Liz Peña, Alejandra Maldonado, Aldeni Vasquez, Aldrin Lopez

Belize: Lilly Mahung, Diomar Salazar

Guatemala: Fernanda Kroker, Maria Alejandra Cordova,

Regina Garcia, Lilian Navas

El Salvador: Josefina Sibrian, Mauricio Flores, Noel Avalos

Honduras: Astarte Alegria, Jorge A. Sierra, Hector Murillo

Nicaragua: Ana María Gutierrez, Carmen María Flores, Mario Romero

Costa Rica: Emilce Ulate, Natalia Valverde, Andrea Fiatt, Juan Manuel Valverde

Panama: Flavia Fontes, Raisa Rodriguez, Emerita Pons, Lino Chue, Elka Gonzalez

Dominican Republic: Rafael Montero, Francisco Torres, Amarilis Then, Melvi Perez

\section{AUTHOR CONTRIBUTIONS}

KSF performed the data analysis and KSF and EV drafted the manuscript. EV, AVR, and MRZ designed the Nine Countries Metabolic Syndrome Study, AVR and MRZ oversaw data collection. KSF, ECJ, and KMR optimized the telomere measurement protocol and quantified LTL, and LSR provided necessary laboratory expertise and resources. All authors read and approved the final version of the manuscript.

\section{REFERENCES}

Aviv, A. (2009). Leukocyte telomere length: The telomere tale continues. American Journal of Clinical Nutrition, 89, $1721-1722$.

Blackburn, E. H. (2005). Telomeres and telomerase: Their mechanisms of action and the effects of altering their functions. FEBS Letters, 579, 859-862.

Broer, L., Codd, V., Nyholt, D. R., Deelen, J., Mangino, M., Willemsen, G., ... Boomsma, D. I. (2013). Meta-analysis of telomere length in 19713 subjects reveals high 
heritability, stronger maternal inheritance and a paternal age effect. European Journal of Human Genetics, 21, 1163-1168.

Carroll, J. E., Diez-Roux, A. V., Adler, N. E., \& Seeman, T. E. (2013). Socioeconomic factors and leukocyte telomere length in a multi-ethnic sample: Findings from the multiethnic study of atherosclerosis (MESA). Brain, Behavior, and Immunity, 28, 108-114.

Cawthon, R. M. (2009). Telomere length measurement by a novel monochrome multiplex quantitative PCR method. Nucleic Acids Research, 37, e21.

Cui, Y., Gao, Y.-T., Cai, Q., Qu, S., Cai, H., Li, H.-L., .. . Zheng, W. (2013). Associations of leukocyte telomere length with body anthropometric indices and weight change in chinese women. Obesity, 21, 2582-2588.

Dalgård, C., Benetos, A., Verhulst, S., Labat, C., Kark, J. D., Christensen, K., ... Aviv, A. (2015). Leukocyte telomere length dynamics in women and men: Menopause vs age effects. International Journal of Epidemiology, 44, 1688-1695.

Eisenberg, D. T. A., Salpea, K. D., Kuzawa, C. W., Hayes, M. G., \& Humphries, S. E., \& European Atherosclerosis Research Study II Group. (2011). Substantial variation in qPCR measured mean blood telomere lengths in young men from eleven European countries. American Journal of Human Biology, 23, 228-231.

Epel, E. S., Blackburn, E. H., Lin, J., Dhabhar, F. S., Adler, N. E., Morrow, J. D., \& Cawthon, R. M. (2004). Accelerated telomere shortening in response to life stress. Proceedings of the National Academy of Sciences of the United States of America, 101, 17312-17315.

Fernández-Alvira, J. M., Fuster, V., Dorado, B., Soberón, N., Flores, I., Gallardo, M., ... Andrés, V. (2016). Short telomere load, telomere length, and subclinical atherosclerosis: The PESA study. Journal of the American College of Cardiology, 67, 2467-2476.

Fitzpatrick, A. L., Kronmal, R. A., Gardner, J. P., Psaty, B. M., Jenny, N. S., Tracy, R. P., ... Aviv, A. (2007). Leukocyte telomere length and cardiovascular disease in the cardiovascular health study. The American Journal of Epidemiology, 165, 14-21.

Gardner, M., Bann, D., Wiley, L., Cooper, R., Hardy, R., Nitsch, D., ... Ben-Shlomo, Y. (2014). Gender and telomere length: Systematic review and meta-analysis. Experimental Gerontology, 51, 15-27.

Haycock, P. C., Heydon, E. E., Kaptoge, S., Butterworth, A. S., Thompson, A., \& Willeit, P. (2014). Leucocyte telomere length and risk of cardiovascular disease: Systematic review and meta-analysis. BMJ, 349, g4227.

Ilmonen, P., Kotrschal, A., \& Penn, D. J. (2008). Telomere attrition due to infection. PLoS One, 3, e2143.

Iwama, H., Ohyashiki, K., Ohyashiki, J. H., Hayashi, S., Yahata, N., Ando, K., ... Shay, J. W. (1998). Telomeric length and telomerase activity vary with age in peripheral blood cells obtained from normal individuals. Human Genetics, 102, 397-402.

Lee, J.-Y., Jun, N.-R., Yoon, D., Shin, C., \& Baik, I. (2015). Association between dietary patterns in the remote past and telomere length. European Journal of Clinical Nutrition, 69, 1048-1052.

Lin, J., Epel, E., Cheon, J., Kroenke, C., Sinclair, E., Bigos, M., ... Blackburn, E. (2010). Analyses and comparisons of telomerase activity and telomere length in human $\mathrm{T}$ and B cells: Insights for epidemiology of telomere maintenance. Journal of Immunological Methods, 352, 71-80.

Liu, Y., Njai, R. S., Greenlund, K. J., Chapman, D. P., \& Croft, J. B. (2014). Relationships between housing and food insecurity, frequent mental distress, and insufficient sleep among adults in 12 US states, 2009. Preventing Chronic Disease, 11, E37.

Müezzinler, A., Zaineddin, A. K., \& Brenner, H. (2014). Body mass index and leukocyte telomere length in adults: A systematic review and meta-analysis. Obesity Reviews, 15, 192-201.

Næss, A. B., \& Kirkengen, A. L. (2015). Is childhood stress associated with shorter telomeres? Tidsskr nor Laegeforen, 135, 1356-1360.

Needham, B. L., Rehkopf, D., Adler, N., Gregorich, S., Lin, J., Blackburn, E. H., \& Epel, E. S. (2015). Leukocyte telomere length and mortality in the National Health and Nutrition Examination Survey, 1999-2002. Epidemiology, 26, 528-535.

Nettleton, J. A., Diez-Roux, A., Jenny, N. S., Fitzpatrick, A. L., \& Jacobs, D. R. Jr. (2008). Dietary patterns, food groups, and telomere length in the Multi-Ethnic Study of Atherosclerosis (MESA). American Journal of Clinical Nutrition, 88, 1405-1412.

Njajou, O. T., Cawthon, R. M., Damcott, C. M., Wu, S.-H., Ott, S., Garant, M. J., ... Hsueh, W.-C. (2007). Telomere length is paternally inherited and is associated with parental lifespan. Proceedings of the National Academy of Sciences, 104, 12135-12139.

Nordfjäll, K., Svenson, U., Norrback, K.-F., Adolfsson, R., \& Roos, G. (2009). Large-scale parent-child comparison confirms a strong paternal influence on telomere length. European Journal of Human Genetics, 18, 385-389.

O’Donnell, C. J., Demissie, S., Kimura, M., Levy, D., Gardner, J. P., White, C., ... Aviv, A. (2008). Leukocyte telomere length and carotid artery intimal medial thickness: The Framingham Heart Study. Arteriosclerosis Thrombosis and Vascular Biology, 28, 1165-1171.

de Onis, M. (2007). Development of a WHO growth reference for school-aged children and adolescents. The Bulletin of the World Health Organization, 85, 660-667.

Paul, L. (2011). Diet, nutrition and telomere length. Journal of Nutritional Biochemistry, 22, 895-901.

Pearce, M. S., Mann, K. D., Martin-Ruiz, C., Parker, L., White, M., von Zglinicki, T., \& Adams, J. (2012). 
Childhood growth, IQ and education as predictors of white blood cell telomere length at age 49-51 years: The Newcastle Thousand Families Study. PLoS One, 7, e40116.

Pérez-Escamilla, R., Melgar-Quiñonez, H., Nord, M., Álvarez, M., \& Segall-Correa, A. (2007). Escala Latinoamericana y Caribeña de Seguridad Alimentaria (ELCSA) [Latin American and Caribbean Food Security Scale]. Perspectivas en Nutrición Humana, Supplement, 117-134.

Perneger, T. V. (1998). What's wrong with Bonferroni adjustments. BMJ, 316, 1236-1238.

Rehkopf, D. H., Dow, W. H., Rosero-Bixby, L., Lin, J., Epel, E. S., \& Blackburn, E. H. (2013). Longer leukocyte telomere length in Costa Rica's Nicoya Peninsula: A population-based study. Experimental Gerontology, 48, 1266-1273.

Rehkopf, D. H., Dow, W. H., Rosero-Bixby, L., Lin, J., Epel, E. S., \& Blackburn, E. H. (2014). Seasonal variation of peripheral blood leukocyte telomere length in Costa Rica: A population-based observational study. American Journal of Human Biology, 26, 367-375.

Rivera-Andrade, A., \& Luna, M. A. (2014). Trends and heterogeneity of cardiovascular disease and risk factors across Latin American and Caribbean countries. Progress in Cardiovascular Diseases, 57, 276-285.

Robertson, T., Batty, G. D., Der, G., Fenton, C., Shiels, P. G., \& Benzeval, M. (2013). Is socioeconomic status associated with biological aging as measured by telomere length? Epidemiologic Reviews, 35, 98-111.

Salpea, K. D., Talmud, P. J., Cooper, J. A., Maubaret, C. G., Stephens, J. W., Abelak, K., \& Humphries, S. E. (2010). Association of telomere length with type 2 diabetes, oxidative stress and UCP2 gene variation. Atherosclerosis, 209, 42-50.

Schürks, M., Prescott, J., Dushkes, R., De Vivo, I., \& Rexrode, K. M. (2013). Telomere length and ischaemic stroke in women: A nested case-control study. European Journal of Neurology, 20, 1068-1074.

Shalev, I., Entringer, S., Wadhwa, P. D., Wolkowitz, O. M., Puterman, E., Lin, J., \& Epel, E. S. (2013). Stress and telomere biology: A lifespan perspective. Psychoneuroendocrinology, 38, 1835-1842.

Silventoinen, K. (2003). Determinants of variation in adult body height. Journal of Biosocial Science, 35, 263-285.

Starkweather, A. R., Alhaeeri, A. A., Montpetit, A., Brumelle, J., Filler, K., Montpetit, M., ... Jackson-Cook, C. K. (2014). An integrative review of factors associated with telomere length and implications for biobehavioral research. Nursing Research, 63, 36-50.

Steckel, R. H. (2009). Heights and human welfare: Recent developments and new directions. Explorations in Economic History, 46, 1-23.

Subramanian, S. V., Özaltin, E., \& Finlay, J. E. (2011). Height of nations: A socioeconomic analysis of cohort dif- ferences and patterns among women in 54 low- to middleincome countries. PLoS One, 6, e18962.

Tarasuk, V. S. (2001). Household food insecurity with hunger is associated with women's food intakes, health and household circumstances. Journal of Nutrition, 131, 2670-2676.

Valdes, A., Andrew, T., Gardner, J., Kimura, M., Oelsner, E., Cherkas, L., ... Spector, T. (2005). Obesity, cigarette smoking, and telomere length in women. The Lancet, 366, 662-664

Villamor, E., \& Bosch, R. J. (2015). Optimal treatment of replicate measurements in anthropometric studies. Annals of Human Biology, 42, 507-510.

Villamor, E., Finan, C. C., Ramirez-Zea, M., Roman, A. V. \& Nine Mesoamerican Countries Metabolic Syndrome Study (NiMeCoMeS) Group. (2016). Prevalence and sociodemographic correlates of metabolic syndrome in school-aged children and their parents in nine Mesoamerican countries. Public Health Nutrition, 9, 1-11.

Weigel, M. M., \& Armijos, M. M. (2015). Food insufficiency in the households of reproductive-age Ecuadorian women: Association with food and nutritional status indicators. Ecology of Food and Nutrition, 54, 20-42.

Wentzensen, I. M., Mirabello, L., Pfeiffer, R. M., \& Savage, S. A. (2011). The association of telomere length and cancer: A meta-analysis. Cancer Epidemiology, Biomarkers \& Prevention, 20, 1238-1250.

White, H. (1980). A heteroskedasticity-consistent covariance matrix estimator and a direct test for heteroskedasticity. Econometrica, 48, 817-838.

World Health Organization. (1995). Physical status: the use and interpretation of anthropometry. Report of a WHO Expert Committee. WHO Technical Report Series, 854, 1452. Geneva, Switzerland.

Zhao, J., Miao, K., Wang, H., Ding, H., \& Wang, D. W. (2013). Association between telomere length and type 2 diabetes mellitus: A meta-analysis. PLoS One, 8, Se79993.

\section{SUPPORTING INFORMATION}

Additional Supporting Information may be found online in the supporting information tab for this article

How to cite this article: Flannagan KS, Jansen EC, Rozek LS, Rentschler KM. Sociodemographic correlates and family aggregation of leukocyte telomere length in adults and children from Mesoamerica. Am J Hum Biol. 2017;29:e22942. https://doi.org/10.1002/ ajhb.22942 